\title{
Habituation to Auditory Stimuli by Captive African Elephants (Loxodonta africana)
}

\author{
Sarah E. Goodyear ${ }^{1 *}$ and Bruce A. Schulte ${ }^{1}$ \\ ${ }^{1}$ Western Kentucky University \\ *Corresponding author (Email: sarahgoodyear@ymail.com)
}

Citation - Goodyear, S. E., \& Schulte, B. A. (2015). Habituation to auditory stimuli by captive African elephants (Loxodonta africana). Animal Behavior and Cognition, 2(4), 292-312. doi: 10.12966/abc.11.01.2015

\begin{abstract}
Habituation is a major concern for the development of effective, long-term human-wildlife conflict mitigation and zoo enrichment programs. Elephants are cognitive species that exhibit many types of learning, such as associative, social, and insight learning. However, no study has examined the habituation process in elephants. Elephants possess a well-developed sensory system and may habituate to stimuli that could be used for enrichment and/or management. The aim of this study was to examine their habituation process in response to repeated presentations of two auditory stimuli: buzzing by a disturbed beehive and the sound created by banging on pots and pans, and in comparison to no sound trials. The selected sounds often invoke alert behaviors and movements in wild elephants as part of human-elephant conflict mitigation. We predicted that elephants would initially exhibit strong reactions to both sounds, but these responses would diminish over repeated trials. This study was conducted with four female African elephants (Loxodonta africana) at the Nashville Zoo in Tennessee. During the first sound presentation, the elephants reacted by showing distress, avoidance, and vigilance behaviors. Over repeated presentations, their reactions to the sounds diminished to levels observed during the no-sound trials, suggesting habituation had occurred. The elephants also reduced their response to the second sound more rapidly than to the first sound, suggesting that generalization of their habituation had occurred. The results support our hypothesis that elephants use habituation to learn which stimuli are non-threatening and subsequently stop responding to them. Habituation is an important learning process that should be considered during the implementation of captive and wildlife management, especially for highly intelligent species, such as elephants.
\end{abstract}

Keywords - Learning, Crop raiding, Human-elephant conflict, Human-wildlife conflict, Enrichment

Habituation is a learning process in which the strength of an individual's response to a particular stimulus decreases with repeated presentations of that stimulus (Thompson \& Spencer, 1966). This reduction occurs as the individual learns that the stimulus is neither threatening nor meaningful (McSweeney \& Swindell, 2002). Furthermore, as an individual habituates to a stimulus, it becomes more tolerant of the stimulus and requires an increasingly higher stimulus intensity to respond (Bejder, Samuels, Whitehead, Finn, \& Allen, 2009). Habituation to one stimulus can also be generalized to another stimulus if it is similar to the first and also non-threatening; generalization of habituation can result in individuals reducing their responses to the second stimulus faster than they would in the absence of the first stimulus (Sarkar, 2003). The occurrence and rate of habituation can be affected by properties of the stimulus such as intensity, frequency, and variability, as well as the biological importance of responding (Groves, Lee, \& Thompson, 1969). Specifically, the process of habituation should not occur as rapidly, or at all, when the response to the stimulus is important for an individual's survival and/or reproduction (Eisenstein, Eisenstein, \& Smith, 2001; Groves \& Thompson, 1970). 
Habituation is widespread across taxa, from sea slugs (Tritonia diomedea) to species with advanced cognitive abilities, such as primates, corvids, and dolphins (Breiter et al., 1996; Brown, 1998; Clayton \& Emery, 2005; Connor \& Smolker, 1985; Johns, 1996). African (Loxodonta africana) and Asian (Elephas maximus) elephants are also considered highly intelligent species (Bates, Poole, \& Byrne, 2008; Foerder, Galloway, Barthel, Moore, \& Reiss, 2011), although comparative cognitive studies between the two have not been performed. The ability to stop responding to repeated, nonthreatening stimuli reduces the energy wasted on vigilance and avoidance behavior in both wild and captive settings. Elephants perceive their environment through multiple sensory modalities, though they seem to rely more on audition and olfaction than vision (Langbauer, 2000; Plotnik et al., 2013; Rasmussen \& Schulte, 1998). Because of this, elephants may be more likely to exhibit their learning abilities through olfaction and audition (Irie \& Hasegawa, 2009). Both African and Asian elephants can use auditory cues to distinguish between different threats (McComb, Shannon, Sayialel, \& Moss, 2014; Soltis, King, Douglas-Hamilton, Vollrath, \& Savage, 2014; Thuppil \& Coss, 2013), and for socialization, with many of their calls employed to share information between family and bond members (Irie \& Hasegawa, 2009; Poole, Tyack, Stoeger-Horwath, \& Watwood, 2005). By learning to not respond to unimportant stimuli, elephants can attend to crucial stimuli, such as vocalizations from their family group, mating pheromones, or predator cues.

Elephants in captivity receive frequent stimulation from their environment. Some stimulation is an unintentional by-product of human activity, including zoo visitors, exhibit construction, and maintenance. Enrichment items are deliberately provided to encourage the elephants to interact more with their environment and maintain their mental and physical wellbeing in captivity (Stoinski, Daniel, \& Maple, 2000; Wells \& Irwin, 2008; Wiedenmayer, 1998). However, when enrichment items are presented multiple times, elephants may gradually habituate to them, rendering them ineffective. Understanding their habituation process will help facilities use enrichment that stimulates learning and decision-making in captive individuals while remaining effective over time. Furthermore, knowledge on elephant habituation will help in the development of successful, long-term deterrents in human-elephant conflict (HEC) mitigation.

HEC has increasingly become a larger problem because of habitat fragmentation and loss in Africa and Asia, with crop raiding being a predominant form of conflict (Nelson, Bidwell, \& Sillero-Zubiri, 2003; Oswin Perera, 2009). Both humans and elephants suffer negative consequences from HEC. In order to protect their crops, property, and already modest income, farmers may shoot the raiding elephant or any nearby elephant. In addition, crop protection can be extremely dangerous for farmers, as they can also become injured or killed during their interactions with the raiding elephant (Hill, 1997; Osborn \& Parker, 2002; Sitati, Walpole, Smith, \& Leader-Williams, 2003). The detrimental effects of crop raiding have motivated the implementation of various deterrents to keep animals from entering farms (Nelson et al., 2003; Oswin Perera, 2009). These deterrents can range from watchtowers and alarm systems to physical barriers like trenches, walls, and fences (Nelson et al., 2003; Osborn \& Parker, 2002). Unfortunately, many of these deterrents have proven to be ineffective for long-term mitigation because, after repeated exposure, animals appear to habituate to them or find means to circumvent them (Davies et al., 2011; Hoare, 2011; Nyirenda, Myburgh, \& Reilly, 2012).

One potential deterrent that has recently gained popularity in HEC mitigation is the sound of disturbed bees buzzing. Wild elephants avoid locations where actual beehives are present, as well as where bee buzzing sounds are played (King, Lawrence, Douglas-Hamilton, \& Vollrath, 2009; Vollrath \& DouglasHamilton, 2002). In their natural habitat, bee buzzing represents an evolutionarily beneficial signal that informs an elephant that it is approaching a threat. Although elephants have incredibly thick skin, they can be extremely sensitive to bee stings near their eyes, behind their ears, and under and inside their trunk (Vollrath \& Douglas-Hamilton, 2002). Moreover, the African honeybee (Apis mellifera scutellata) is known to attack in swarms, so an elephant that disturbs a hive is at risk of being stung repeatedly (Breed, Guzmán-Novoa, \& Hunt, 2004). Consequently, it would be evolutionarily beneficial for elephants to know that the sound of disturbed bees signals the presence of a potential threat. It is currently unknown, though, whether their response to bees is innate or acquired through social or associative learning. 
Although bee colonies situated at the edges of crop fields (hereafter 'beehive fences') currently seem to be successful at deterring elephants from crop raiding, their long-term effectiveness is still unknown. As most crop raiding occurs at night and bees are typically less active then, frequent raiders may habituate to inactive beehive fences during evening crop raids (Hoare, 2011). Elephants may, alternatively, learn to display different tactics to avoid bee stings while entering the crop field. Furthermore, it has also been suggested that just the sound of an agitated beehive might be effective at deterring elephants (King, Douglas-Hamilton, \& Vollrath, 2007; King et al., 2009). However, elephants may begin to habituate to the sound of bees when actual bees and subsequent stinging are not present. Similar results have been seen with other auditory stimuli that do not include a form of punishment, such as banging on drums or pots and pans (De Boer \& Baquete, 1998; Nelson et al., 2003). Thus, it is important to understand how elephants' responses to stimuli change with repeated presentations.

The aim of the present study was to examine the process by which elephants cease to respond to repeated presentations of two auditory stimuli: the sound of disturbed bee buzzing and the sound produced from banging on pots and pans. These sounds were chosen because they often invoke alert behaviors and avoidance in wild elephants, and either are currently used (pots/pans) or are under study (bees) to be used for large-scale use as deterrents in HEC mitigation. As discussed previously, bee buzzing is a biological warning to elephants that a threat (bee swarm or beehive) is nearby. Farmers bang pots and pans together to create a sound that can be loud and unusual to crop raiders (Nelson et al., 2003). We predicted that elephants would initially exhibit strong distress, avoidance, and vigilance reactions to both sounds, but as no punishment would occur, these responses would diminish over repeated trials as the elephants habituated. Because of the evolutionary significance of bee buzzing, we also predicted that elephants would take longer to reduce their responses to the bee sound compared to the pots/pans sound. Additionally, as this study was conducted using captive elephants, the elephants may generalize between the normal loud zoo-related sounds and the pots/pans sound, and more quickly reduce their reactions to the pots/pans sound (Morgan \& Tromborg, 2007; Sarkar, 2003).

\section{Method}

\section{Subjects}

All trials for this study occurred at the Nashville Zoo in Nashville, TN during the summer of 2014. The study subjects were four female adult African elephants: Hadari, Sukari (hereby Suki), Rosie, and Juno. All four elephants were wild-born and transferred to American captive facilities as calves during the 19701980s. Rosie and Juno have been together for 32 years, 28 years at the Jackson Zoo and 4 years at the Nashville Zoo. Hadari and Suki have been together for 15 years at the Nashville Zoo. Hadari has been on behavioral medication for around 10 years; during this study, she was taking Trazadone and Fluoxetine.

\section{Data Collection}

This study included two trial sets, with three weeks for each trial set; no trials were run on weekends because of the higher number of guests and work requirements on the elephant handlers during those days (Table 1). A trial set included one week of "no-sound" trials (comprised of two food training (FT) and three control sound (CS) trials) and then two weeks of experimental sound (S) trials (S1-S10). The no-sound trials were used to establish baseline levels; these were compared to the response levels during the experimental sound trials to evaluate the initial responses of the elephants to each sound. Elephants were considered habituated when their responses returned to baseline levels during the sound treatment. 
Table 1

Schedule for the Two Experimental Trial Sets

\begin{tabular}{|c|c|c|c|c|c|c|}
\hline & & Monday & Tuesday & Wednesday & Thursday & Friday \\
\hline \multirow{3}{*}{ TS1 } & Week 1 & Foo & aing & \multicolumn{3}{|c|}{ Control Sound } \\
\hline & Week 2 & \multicolumn{5}{|c|}{ Experimental Sound } \\
\hline & Week 3 & \multicolumn{5}{|c|}{ Experimental Sound } \\
\hline \multirow{3}{*}{ TS2 } & Week 1 & Foo & ning & \multicolumn{3}{|c|}{ Control Sound } \\
\hline & Week 2 & \multicolumn{5}{|c|}{ Experimental Sound } \\
\hline & Week 3 & \multicolumn{5}{|c|}{ Experimental Sound } \\
\hline
\end{tabular}

Note: Week 1 of each trial set was no-sound trials, including two food training trials and three control sound trials. Week 2 and Week 3 were experimental sound trials. During Trial Set (TS) 1, Hadari and Suki received the bee sound, while Rosie and Juno received the pots/pans sound. During TS2, Hadari and Suki received the pots/pans sound, while Rosie and Juno received the bee sound.

Acclimation to experimental set-up. Before the trial sets began, the elephants underwent nine days of location training. This included six FT trials and three CS trials. These trials were conducted to provide the elephants with the opportunity to acclimate to the experimental set up. Specifically, the trials were used to teach the elephants to expect food at either four (FT) or one (CS) experimental location(s) (Figure 1), as the elephants typically received food presented throughout the yard during their morning releases. The trials also allowed the elephants to acclimate to a different yard-release schedule. On their normal schedule, all four elephants were released into the yard together in the morning at 900 and stayed there until 1200. However, during this study, the elephants were brought into the yard separately in pairs, returned to the barn after their specific trial ended, and then released together at 1000 (see below). In addition, the CS trials were conducted in order to control for the presence of the speaker emitting a signal in the yard. Because the data collected during location training may have been influenced by the elephants' acclimation to the experimental set up, these data were not used to examine the study's hypotheses.

For each trial, the elephants were brought into the yard as separate pairs. The elephants were tested as pairs rather than individually because of the zoo's protocol for separating their elephants, as well as husbandry concerns for how separating the two elephants in a single pair would influence the elephants' behaviors during the trials. Hadari and Suki were brought out first ( 900) and Rosie and Juno were brought out second ( 930$)$; the only exception to this was Trial Set 1's sound trial 5, which started at 800 because of a scheduling conflict with the zoo. The elephant handers walked the elephants out of the barn and to the middle yard, where the elephants were released and allowed to go anywhere in the yard (see " $R$ " in Figure 1). For CS and S trials, the sound started when the first elephant touched the food at the experimental location. The trial continued until both elephants walked to the top doorway and the handlers brought them back into the barn $(\bar{X} \pm \mathrm{SD}=21.1 \pm 4.2 \mathrm{~min}$ (Hadari, Suki), $18.7 \pm 3.2 \mathrm{~min}$ (Rosie, Juno)). A focal observation was done on each elephant during the entire trial (enter yard to exit yard) using a full ethogram of elephant states and events. Video was also recorded using Sanyo Digital Camera Model VPC-E870 and/or Panasonic HX-WA03 14.4 MP camcorders. 


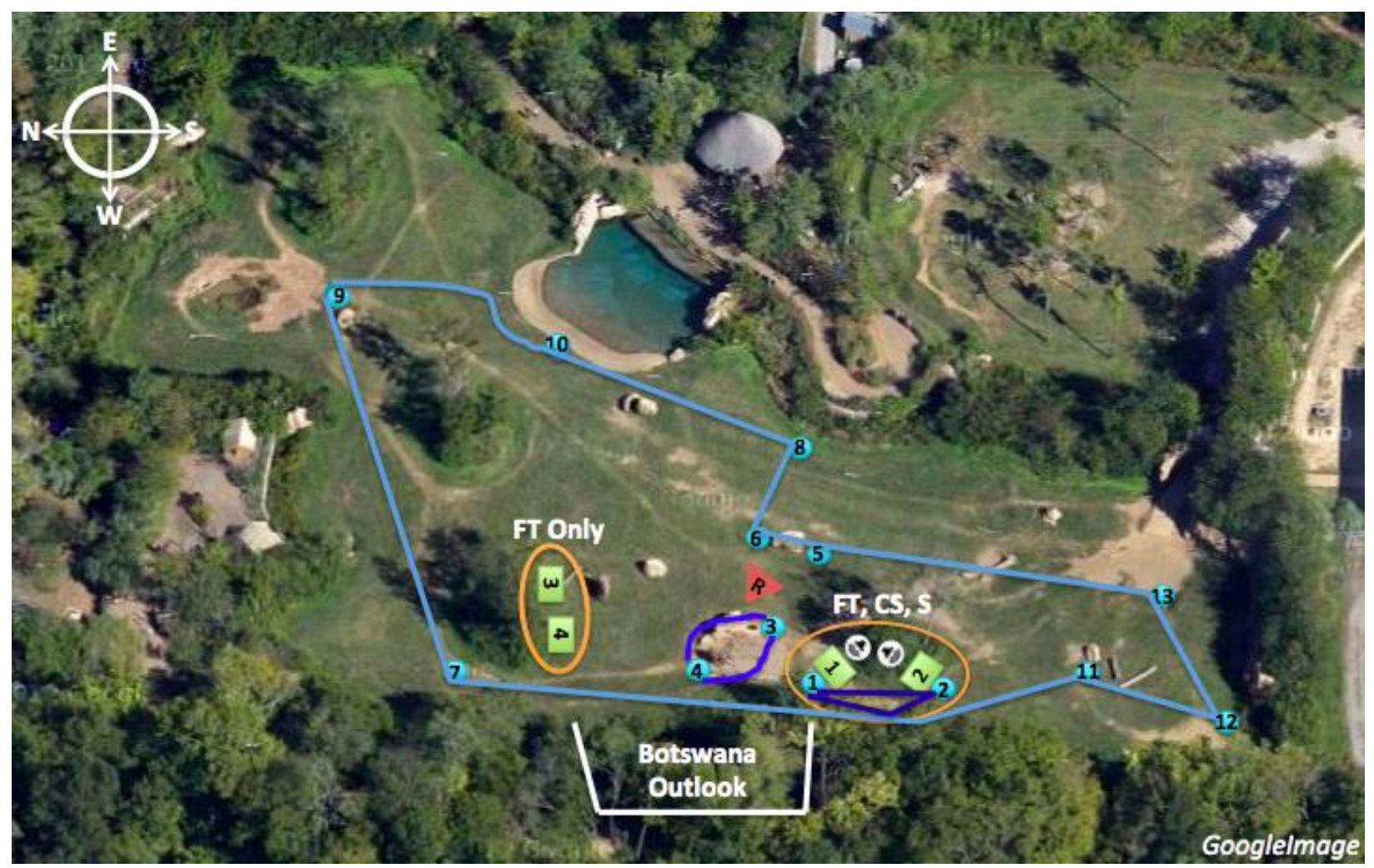

Figure 1. An aerial view of the Botswana Elephant Yard at the Nashville Zoo. The white line outlines the location of Botswana Outlook, where most observations were conducted during this study. The experimental locations are indicated by green rectangles with their specified numbers $(1,2,3,4)$ in black; the rectangles' placements is where the food was placed by elephant handlers. Locations 1 and 2 were used during the food training (FT), control sound (CS), and sound (S) trials, while Location 3 and 4 were only used during the FT trials. Speaker images ( $)$ at Location 1 and 2 represent the speaker's location inside the bushes during the CS and S trials. The red triangle with "R" shows the location where the elephant pair was released by their handlers at the start of each trial. Blue circles are where sound intensities of the experimental sounds were tested using a Hand-held Analyzer Type 2250 (Brüel \& Kjær, Nærum, DK). The blue lines connect points of similar sound intensity; lightest blue line $=\sim 40-49 \mathrm{~dB}$, blue line connecting 3 and $4=\sim 50-59 \mathrm{~dB}$, and the darkest blue line $=\sim>60 \mathrm{~dB}$ (re $20 \mu \mathrm{Pa}$ ) (specific sound intensity measurements corresponding with each blue circle can be obtained by contacting the corresponding author or see Goodyear (2015)). Typically, the pots/pans sound had a higher intensity at each location than the bee sound (e.g., at food location, bee $=66 \mathrm{~dB}$, pots/pans $=71$ $\mathrm{dB})$.

Control and experimental sounds. The control sound was created by recording no audible sound (complete silence measured at $0 \mathrm{~dB}$, re $20 \mu \mathrm{Pa}$ ) for $30 \mathrm{~s}$ using GarageBand '11 Version 6.0.4 (427.84). An inaudible sound was used because it was observed that the speaker would lose connection with the transmitter and produce static if no sound was emitted for over five minutes. The recording was looped to create a 10-min sound using GarageBand and exported to iTunes Version 11.1.4 (62) as an mp3. A playlist containing three 10-min control sounds was created so that the control sound could continuously play for $30 \mathrm{~min}$, the expected maximum length of a trial.

There were two experimental sounds used in this study: the sound of disturbed bee buzzing and the sound of pots and pans banging. The bee sound was acquired from Audiosparx (www.audiosparx.com), titled "B, Swarm of Bees 002" (Catalog ID: 463719) by The Producers. The initial version of this sound (36 s) was cut to $30 \mathrm{~s}$, looped to create a 4-min sound, and exported to iTunes. The pots/pans sound was created in GarageBand by recording the sound of the PI banging on a frying pan and a small metal pot for $30 \mathrm{~s}$. The recording was looped to create a 4-min sound and exported to iTunes. A separate playlist was made for each sound that included the 4-min experimental sound and then three 10-min control sounds. 
During CS and S trials, the speaker was set at its highest volume and placed in the bushes at the experimental location. The speaker was autotuned to the transmitter, which was connected to a 2011 13-in MacBook Pro. Recordings of the experimental sounds' intensities were taken throughout the yard using a Hand-held Analyzer Type 2250 (Brüel \& Kjær, Nærum, DK) while the speaker, at Location 1 and then 2, played each sound (Figure 1). At the food location ( 1.5 m away from the speaker), the average intensity was $66 \mathrm{~dB}$ for the bee sound and $71 \mathrm{~dB}$ for the pots/pans sound (re $20 \mu \mathrm{Pa}$ ). Sound frequencies were examined using Audacity. The maximum peak frequencies ranged from $435-531 \mathrm{~Hz}$ for the bee sound and $1000-2500 \mathrm{~Hz}$ for the pots/pans sound. The authors do not believe that the elephant pair left within the barn could hear the sounds being played to the other pair in the yard. The elephant keepers in the barn did not observe any obvious behavioral reactions from the indoor elephants during any trial of the experiment. The elephant barn walls are extremely thick and made out of concrete, which could have aided in the sound obstruction.

No-sound trials. During the two FT trials, food but no speaker, was placed at all four experimental locations (Figure 1). During the CS and S trials, food and the speaker were only placed at either Location 1 or Location 2. Location 3 and Location 4 were not used during sound trials; the speaker (C2G Audio Unlimited Premium 900MHz Wireless Indoor/Outdoor speaker, SPK-VELO-003) regularly emitted static when placed at these locations, probably due to the distance and drop in elevation that may have reduced reception quality. During CS trials, the control sound played for the entire trial, while no sound played during the FT trials. To parallel the experimental sound trials, the first four minutes after the first elephant touched the food was considered the "sound playback period" for FT and CS trials.

Experimental sound trials. After the week of no-sound trials, each elephant pair was played an experimental sound once a day for two weeks; however, due to traffic, the researchers arrived too late to conduct Trial Set 2's S7. During Trial Set 1 (TS1), Hadari and Suki received the bee sound, while Rosie and Juno received the pots/pans sound. During Trial Set 2 (TS2), the sounds played to each pair switched so that Hadari and Suki received the pots/pans sound, while Rosie and Juno received the bee sound. With this experimental design, all four elephants received both sounds, while allowing order effects and generalization of habituation to be examined. All observations were conducted from the Botswana Outlook, which is a viewing area restricted for private receptions adjacent to the elephant yard (Figure 1). During S trials, the experimental sound played for four minutes and then the control sound played for the rest of the trial.

\section{Response Variables}

Due to the small sample size $(N=4)$, statistical analyses were not conducted for this study. However, following the procedure of other small-N studies in behavioral science, visual analyses were used to examine the change in the response variables between the no-sound trials and sound trials of TS1 and TS2 (e.g., Dinets, 2015; Graham, Karmarkar, \& Ottenbacher, 2012; Osvath, Osvath, \& Bååth, 2014; Whitley \& Kite, 2012). Since there were four elephants, multiple baselines for each response variable were established; this increases the accuracy of examining changes (patterns/trends) in visual analyses (Graham et al., 2012).

Three behavioral responses were examined during the 4-min sound playback period in each trial: distress, avoidance, and vigilance (Table 3). Distress was measured using rates of distress behaviors. Eight behaviors were considered as distress events: alert, ear perk, tail up, headshake, vocalization, toe down, foot up, and temporal streaming (Table 2). Avoidance was measured using proportions of time (expressed as percentages) spent at the experimental location that contained food and the source of the sound; a reduced time spent at the location was considered avoidance. Distress rate and time at the location were examined separately for all four elephants. Vigilance was measured using proportions of time (expressed as percentages) spent standing versus eating. Vigilance was only examined for the first elephant to touch the food at the location. We assumed that an elephant touched the food because she intended to eat it, so any 
deviation from this (to stand rather than eat) may have been in reaction to the sound (i.e., vigilance). This could not be assumed for the second elephant that did not touch the food. These response variables have been used in previous habituation studies on other species (Christensen, Zharkikh, \& Ladewig, 2008; Epple et al., 1995; Roberts, 2014; Ujvári, Baagøe, \& Madsen, 1998; Ylönen, Eccard, Jokinen, \& Sundell, 2006). Previous studies have also noted their occurrences when elephants are responding to perceived threats (Table 2). The three response variables are presented in the text as mean values \pm SD with individual values presented in the figures.

Table 2

Examples and Descriptions from the Literature of Elephants in Distress or Reacting to Perceived Threats

\begin{tabular}{|c|c|c|c|}
\hline Article & Stimulus & Response & Elephants \\
\hline Lee (1987) & Any distressing event & $\begin{array}{l}\text { "A dramatic response on the part of other } \\
\text { animals...rushing to assist the calf" (p. 287) }\end{array}$ & $\begin{array}{l}\text { African; } \\
\text { Adults }\end{array}$ \\
\hline $\begin{array}{l}\text { Osborn \& } \\
\text { Rasmussen } \\
(1995)\end{array}$ & $\begin{array}{l}\text { Oleo-resin capsicum } \\
\text { aerosol }\end{array}$ & $\begin{array}{l}\text { Vigilance (freeze); Avoidance; Distress (headshake, } \\
\text { vocalize, expel air, touched eyes repeatedly) }\end{array}$ & $\begin{array}{l}\text { African; } \\
\text { Cows, Bulls }\end{array}$ \\
\hline Osborn (2002) & $\begin{array}{l}\text { Traditional methods } \\
\text { (guards with fire, making } \\
\text { noise, chasing away); } \\
\text { Capsicum oleoresin } \\
\text { spray }\end{array}$ & $\begin{array}{l}\text { Traditional methods: Avoidance (faster with multiple } \\
\text { farmers chasing than single farmer) } \\
\text { Capsicum spray: Avoidance (faster than traditional); } \\
\text { Vigilance (freeze); Distress (alert, vocalize, expel air, } \\
\text { disoriented) }\end{array}$ & African \\
\hline Olson (2004) & Any distressing event & $\begin{array}{l}\text { Distress (vocalize, alert, tail up, ear perk, trunk raised or } \\
\text { straight outward) }\end{array}$ & $\begin{array}{l}\text { African; } \\
\text { Calves }\end{array}$ \\
\hline $\begin{array}{l}\text { Poole \& Granli } \\
\text { (2004) }\end{array}$ & $\begin{array}{l}\text { Anti-predator, defensive } \\
\text { or fearful contexts }\end{array}$ & $\begin{array}{l}\text { Distress (alert, tail up, widened eyes, curved trunk, look } \\
\text { over shoulder) }\end{array}$ & African \\
\hline $\begin{array}{l}\text { Douglas- } \\
\text { Hamilton et al. } \\
(2006)\end{array}$ & Dying elephant & $\begin{array}{l}\text { Approach; Distress (tail up, temporal secretions, } \\
\text { vocalize); Physical touches (nudge/push with tusk) }\end{array}$ & $\begin{array}{l}\text { African; } \\
\text { Matriarch }\end{array}$ \\
\hline $\begin{array}{l}\text { Bates et al. } \\
(2007)\end{array}$ & $\begin{array}{l}\text { Scent of Maasai men } \\
\text { Colored (red) cloth of } \\
\text { Maasai men }\end{array}$ & $\begin{array}{l}\text { Avoidance; Distress (not relaxed) } \\
\text { Aggressive displays }\end{array}$ & $\begin{array}{l}\text { African; } \\
\text { Family }\end{array}$ \\
\hline $\begin{array}{l}\text { King, Douglas- } \\
\text { Hamilton, \& } \\
\text { Vollrath (2007) }\end{array}$ & Bee buzzing & Avoidance & $\begin{array}{l}\text { African; } \\
\text { Family }\end{array}$ \\
\hline $\begin{array}{l}\text { O’Connell- } \\
\text { Rodwell } \\
\text { (unpublished) } \\
\text { cited by Bouley } \\
\text { (2007) }\end{array}$ & Infrasonic signals & Distress (toe down, rock back onto their heels) & African \\
\hline $\begin{array}{l}\text { O’Connell- } \\
\text { Rodwell \& } \\
\text { Wood (2007) }\end{array}$ & $\begin{array}{l}\text { Infrasonic alarm calls } \\
\text { from familiar elephant } \\
\text { group when hunting lions } \\
\text { were nearby }\end{array}$ & $\begin{array}{l}\text { Vigilance (freeze, lean, scan, smell); Distress (foot up, } \\
\text { headshake, vocalize); Decrease herd spacing }\end{array}$ & $\begin{array}{l}\text { African; } \\
\text { Family }\end{array}$ \\
\hline $\begin{array}{l}\text { Bates et al. } \\
(2008)\end{array}$ & $\begin{array}{l}\text { Another elephant's } \\
\text { distress }\end{array}$ & $\begin{array}{l}\text { "A voluntary, active response to another individual's } \\
\text { current or imminent distress or danger, that actually or } \\
\text { potentially reduces that distress or danger" (p. 208) }\end{array}$ & African \\
\hline $\begin{array}{l}\text { King et al. } \\
\text { (2009) }\end{array}$ & $\begin{array}{l}\text { Farms with beehive } \\
\text { fences }\end{array}$ & Avoidance (fewer raids, with fewer elephants) & African \\
\hline
\end{tabular}


Table 2 (cont.)

\begin{tabular}{|c|c|c|c|}
\hline $\begin{array}{l}\text { Chelliah et al. } \\
(2010)\end{array}$ & Chili-tobacco rope fence & $\begin{array}{l}\text { Avoidance (walk along fence 2-10m away); Sniff toward } \\
\text { fence }\end{array}$ & $\begin{array}{l}\text { African; } \\
\text { Family, Bulls }\end{array}$ \\
\hline $\begin{array}{l}\text { King et al. } \\
(2010)\end{array}$ & $\begin{array}{l}\text { Bee buzzing } \\
\text { Rumble response to bee } \\
\text { buzzing }\end{array}$ & $\begin{array}{l}\text { Avoidance; Distress (vocalize, headshakes, dusting) } \\
\text { Avoidance; Distress (vocalize, headshakes, dusting) }\end{array}$ & $\begin{array}{l}\text { African; } \\
\text { Family }\end{array}$ \\
\hline $\begin{array}{l}\text { Le Bel et al. } \\
(2010)\end{array}$ & $\begin{array}{l}\text { Capsicum delivery: } \\
\text { Catapult or gas-dispenser }\end{array}$ & $\begin{array}{l}\text { Avoidance - occurred whether hit with clay/ping pong } \\
\text { balls or not (sound alone is deterrent too); Bulls more } \\
\text { deterred than cows }\end{array}$ & $\begin{array}{l}\text { African; } \\
\text { Bulls, Cows }\end{array}$ \\
\hline $\begin{array}{l}\text { McComb et al. } \\
(2011)\end{array}$ & $\begin{array}{l}\text { Lion roars } \\
\text { ( } 1 \text { male vs. } 3 \text { females })\end{array}$ & $\begin{array}{l}\text { Vigilance (listen, defense bunching); Approach (by older } \\
\text { matriarchs); Stronger response to } 3 \text { female lions }\end{array}$ & $\begin{array}{l}\text { African; } \\
\text { Family }\end{array}$ \\
\hline $\begin{array}{l}\text { Thuppil \& Coss } \\
\text { (2013) }\end{array}$ & $\begin{array}{l}\text { Tiger growl and Leopard } \\
\text { growl }\end{array}$ & $\begin{array}{l}\text { Tiger growl: Avoidance (quick and silent) } \\
\text { Leopard growl: Avoidance (delayed), Vigilance (stood, } \\
\text { listening and smelling), Distress (alert, "aggressive" } \\
\text { vocalizations) }\end{array}$ & $\begin{array}{l}\text { Asian; Bulls, } \\
\text { Cows, Family }\end{array}$ \\
\hline $\begin{array}{l}\text { McComb et al. } \\
(2014)\end{array}$ & $\begin{array}{l}\text { Voices of Maasai men, } \\
\text { females, boys, and } \\
\text { Kamba men }\end{array}$ & $\begin{array}{l}\text { Defensive bunching; Investigative behavior; responses to } \\
\text { Maasai men greater than to Kamba men, Maasai females, } \\
\text { Maasai boys }\end{array}$ & $\begin{array}{l}\text { African; } \\
\text { Family }\end{array}$ \\
\hline $\begin{array}{l}\text { Plotnik \& de } \\
\text { Waal (2014) }\end{array}$ & $\begin{array}{l}\text { Unseen or seen negative } \\
\text { stimulus } \\
\text { (E.g., conspecific } \\
\text { intimidation or } \\
\text { aggression, group } \\
\text { separation, } \\
\text { environmental threats) } \\
\text { Another elephant's } \\
\text { distress }\end{array}$ & $\begin{array}{l}\text { Distress (vocalize); Physical touches (touch genitals, } \\
\text { mouth, or head with her trunk) }\end{array}$ & Asian; Cows \\
\hline $\begin{array}{l}\text { Soltis et al. } \\
\text { (2014) }\end{array}$ & $\begin{array}{l}\text { Samburu voices } \\
\text { Bee buzzing } \\
\text { Rumble response to } \\
\text { Samburu voices } \\
\text { Rumble response to bee } \\
\text { buzzing }\end{array}$ & $\begin{array}{l}\text { Avoidance, Vigilance, Distress (vocalize) } \\
\text { Avoidance, Vigilance, Distress (vocalize, headshakes) } \\
\text { Avoidance, Vigilance } \\
\text { Avoidance, Vigilance, Distress (headshakes) }\end{array}$ & $\begin{array}{l}\text { African; } \\
\text { Family }\end{array}$ \\
\hline $\begin{array}{l}\text { Thuppil \& Coss } \\
\text { (2015) }\end{array}$ & $\begin{array}{l}\text { Tiger growls, Leopard } \\
\text { growls, Human shouting }\end{array}$ & $\begin{array}{l}\text { Distress (startle response, vocalize); Avoidance (reduced } \\
\text { crop raiding - tiger }>\text { leopard }>\text { human) }\end{array}$ & $\begin{array}{l}\text { Asian; Bulls, } \\
\text { Cows, Family }\end{array}$ \\
\hline
\end{tabular}


Table 3

Definitions of the Three Response Variables

\begin{tabular}{|c|c|}
\hline Distress & $\begin{array}{l}\text { Response to a seen or unseen stimulus that indicates alarm, agitation, or excitement } \\
\text { Measured as rate of distress (number of events/min) }\end{array}$ \\
\hline Alert & Head and shoulders raised. Posture is upright and there is clear tautness in the muscles \\
\hline Ear perk & Ears held erect with head unmoving \\
\hline Foot up & Hold one foot up, typically with knee bent \\
\hline Headshake & $\begin{array}{l}\text { Head is dropped, twisted, and rapidly returned to placed with ears and trunk flailing (Only when } \\
\text { not in the states Dust or Mud) }\end{array}$ \\
\hline Tail up & Tail stiffly pointed up and/or outward \\
\hline Temporal streaming & Liquid secretes out of temporal gland \\
\hline Toe down & Place the anterior-most portion of their foot against ground with all other parts off of the ground \\
\hline Vocalization & Vocal calls are produced by the individual* \\
\hline Avoidance & $\begin{array}{l}\text { The individual leaves and/or does not visit the experimental location } \\
\text { Measured as percentage of time spent at the experimental location }\end{array}$ \\
\hline Experimental location & $\begin{array}{l}\text { Where food was placed by an elephant handler. Also where the source of the sound is located } \\
\text { during control sound and experimental sound trials }\end{array}$ \\
\hline Vigilance & $\begin{array}{l}\text { The first individual to touch the food at the location stands rather than eats the food } \\
\text { Measured as the percentages of time spent standing or eating }\end{array}$ \\
\hline Eat & Consume food (includes gathering with trunk, lifting to mouth, and chewing) \\
\hline Stand & $\begin{array}{l}\text { Remains in the same location for at least two seconds (without exhibiting any other stationary } \\
\text { state, e.g., eat, dust, lie) }\end{array}$ \\
\hline
\end{tabular}

*In the present study, most were rumbles but sound recording and analysis were not performed to clearly distinguish type of vocalization

\section{Results}

\section{General Reactions by First Elephant at Location}

TS1 (First sound). On the first experimental sound trial of TS1, the first elephant of each pair exhibited similar reactions to the sounds. Specifically, Suki (bees) and Rosie (pots/pans) ate for a few seconds at the start of the sound and then, within $10 \mathrm{~s}$, moved a few steps back and began exhibiting distress behaviors. Rosie left the location after $15 \mathrm{~s}$ of standing, while Suki went back to the location and ate for 40 $\mathrm{s}$ before leaving. After leaving the location, both elephants stood for over $50 \%$ of the time and neither ate again during the sound period. In contrast, on the last sound trial, the first elephant of each pair (Hadari, Rosie) showed reduced distress, avoidance, and vigilance behaviors. Both elephants ate at, or close to, the experimental location for 2-4 min. Hadari (bees) did not exhibit any distress behaviors, while Rosie (pots/pans) only exhibited one distress behavior and this was a vocalization in response to Juno's vocalization.

TS2 (Second sound). On the first experimental sound trial of TS2, the first elephants of each pair (Hadari - pots/pans, Rosie - bees) exhibited distress behaviors, but did not avoid the location or stop eating. On the last sound trial, the first elephants (Hadari, Rosie) exhibited no distress, avoidance, or vigilance 
behaviors. However, instead of eating, each elephant used its trunk to pick up mud and throw it on its body (i.e., mudded) for most of the sound-on time at the experimental location.

\section{Distress (Rate of Distress Events During Sound Playback)}

TS1 (First sound). During the no-sound trials (comprised of two food training (FT) and three control sound (CS) trials), distress rates were similarly low for all four elephants $\left(X_{\mathrm{FT}}=0.2 \pm 0.1, X_{\mathrm{CS}}=0.3\right.$ \pm 0.1 events/min) (Figure 2). However, all elephants exhibited elevated distress rates during the first three experimental sound $(\mathrm{S})$ trials $\left(X_{\mathrm{S}}=2.8 \pm 2.4\right.$ distress events/min $)$. The pair of elephants receiving the same sound exhibited similar distress rates, with higher rates exhibited by the two elephants exposed to the pots/pans sound (Rosie: $5.1 \pm 2.4$, Juno: $4.6 \pm 1.0$ events $/ \mathrm{min}$ ) than the two elephants exposed to the bee sound (Hadari: $0.8 \pm 0.3$, Suki: $0.8 \pm 0.4$ events/min) (Figure 2). As the sound trials continued, the rate of distress events exhibited by each elephant gradually decreased to baseline levels (Figure 2). The elephants exhibited baseline distress rates by S4 (Hadari \& Suki, bees) or S8 (Rosie \& Juno, pots/pans).

TS2 (Second sound). Similar to TS1, all four elephants exhibited relatively higher rates of distress events during the first three $\mathrm{S}$ trials $\left(X_{\mathrm{S}}=0.8 \pm 0.5\right.$ distress events $\left./ \mathrm{min}\right)$ compared to the preceding no-sound trials $\left(X_{\mathrm{FT}}=0.2 \pm 0.2, \mathrm{Cs}=0.5 \pm 0.7\right.$ events $\left./ \mathrm{min}\right)$ (Figure 2$)$. However, Suki and Juno both showed elevated distress rates on one of the no-sound trials (CS1); many of the distress events exhibited by Suki and Juno during CS1 were observed when loud construction was occurring near the exhibit and/or when an airplane was flying overhead. When this trial was omitted, their average distress rates during TS2's no-sound trials (Suki: $0.4 \pm 0.2$ events/min, Juno: $0.3 \pm 0.1$ events $/ \mathrm{min}$ ) were similar to their TS1 baseline levels; these average distress rates were used as each elephant's baseline for TS2.

Unlike in TS1, elephants that received the same sound did not show similar distress rates (Figure 2). During the first three pots/pans sound trials, Suki exhibited a higher distress rate $(1.3 \pm 1.1$ events/min) than Hadari $(0.4 \pm 0.7$ events/min). During the first three bee sound trials, Juno exhibited a higher distress rate $(1.2 \pm 0.6$ events $/ \mathrm{min})$ than Rosie $(0.3 \pm 0.4$ events $/ \mathrm{min})$. As the sound trials continued, the elephants' rates of distress events decreased to baseline levels (Figure 2). Hadari (pots/pans) and Rosie (bees) reached baseline levels by S2. Juno (bees) reached baseline levels by S4. Suki (pots/pans) reached baseline levels during S3, though she did increase her distress rate again on S6 - the first sound trial of Sound Week 2. On S10, Suki also exhibited a relatively higher distress rate, but these behaviors were exhibited two minutes into the sound period suggesting that they may not have been due to the sound presentation.

Distress behaviors. Three distress behaviors were almost exclusively observed during the sound period (Figure 2; images of distress behaviors in Figure 3). Tail up only occurred during the sound period; however, Suki never exhibited this behavior. Alert was displayed by all four elephants, but was also observed once during a no-sound trial by Rosie and Juno. Ear perk was also displayed by all four elephants during the sound period, but occurred once during a no-sound trial by Juno and Suki. In contrast, headshake and vocalization were observed during both no-sound and sound trials, suggesting that they could be exhibited by elephants in situations unrelated to the sound. 

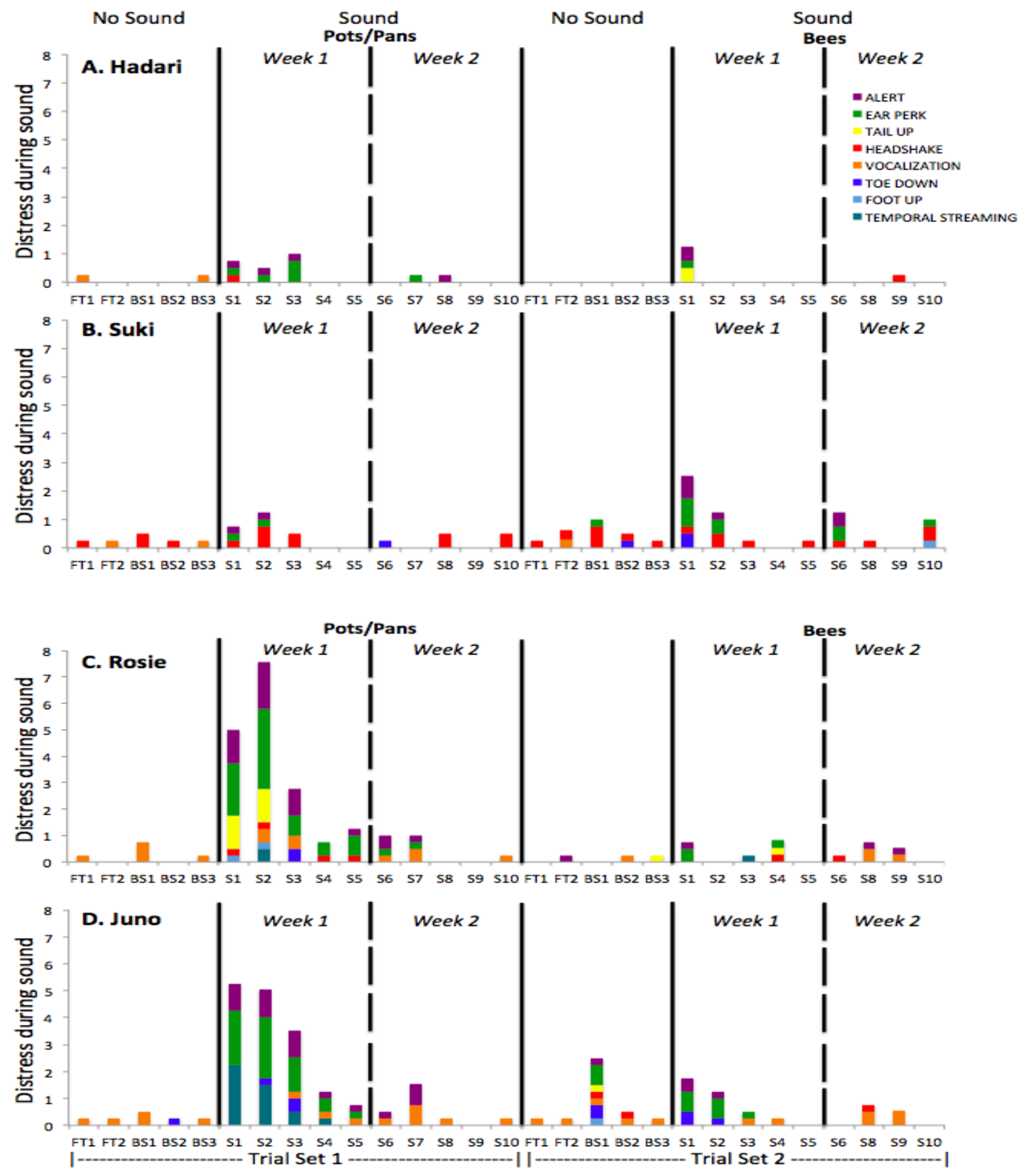

Figure 2. Distress (measured as the rate of distress events, \#/min) during the sound playback period: A. Hadari; B. Suki; C. Rosie; D. Juno. Each trial set includes food training (FT) trials, control sound (CS) trials, and experimental sound (S) trials. Solid black lines separate no-sound and sound treatments; dashed lines separate different weeks of the same sound treatment. 

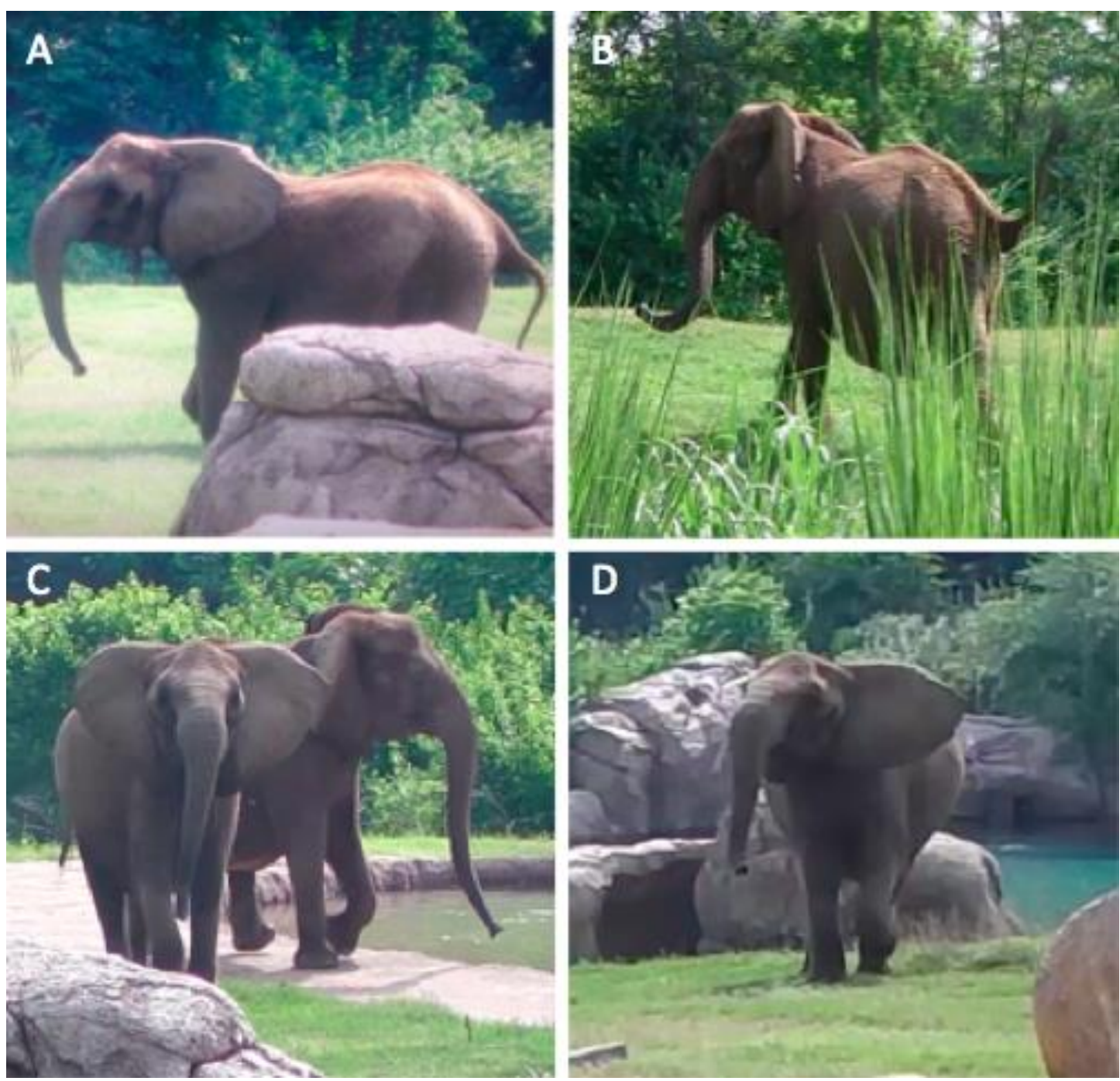

Figure 3. Images of Rosie and Juno exhibiting distress events on the first day of sound (pots/pans). Images A and D show Rosie exhibiting alert, ear perk, foot up, and temporal secretions. Image B shows Juno exhibiting alert, ear perk, and tail up. Image C shows Rosie (left) and Juno (right) exhibiting alert and ear perk; Rosie also exhibiting foot up; Juno also exhibiting toe down. Images acquired from a video taken by Bruce A. Schulte.

\section{Avoidance (\% Time Spent at the Experimental Location(s) During Sound Playback)}

TS1 (First sound). Three of the four elephants - Suki (bees), Rosie and Juno (pots/pans) - spent relatively lower percentages of time at the experimental location during the first three $\mathrm{S}$ trials $\left(X_{\mathrm{S}}=21.1 \pm\right.$ $17.1 \%)$ compared to the three CS trials $\left(X_{\mathrm{CS}}=43.5 \pm 26.0 \%\right)$ (Figure 4). Hadari (bees) was the exception to this pattern; she spent relatively higher percentages of time at the location during the first three $S$ trials $\left(X_{\mathrm{S}}=16.3 \pm 28.1 \%\right)$ compared to baseline $\left(X_{\mathrm{CS}}=7.6 \pm 13.2 \%\right)$. However, Hadari did not go to the location on four of these six trials; thus, her percentage of time spent at the experimental location may not be a good measure of her reaction to the sound, as she did not visit the location on two CS trials and two S trials. By Sound Week 2, all four elephants increased their percentages of time spent at the experimental location $\left(X_{\mathrm{S} 6, \mathrm{~S} 7}=58.0 \pm 41.7 \%\right)$ (Figure 4). However, Suki only spent $4 \%$ of the sound-on time at the location during S7 and stopped visiting to the location on S8. She did not visit the location again during TS1. 

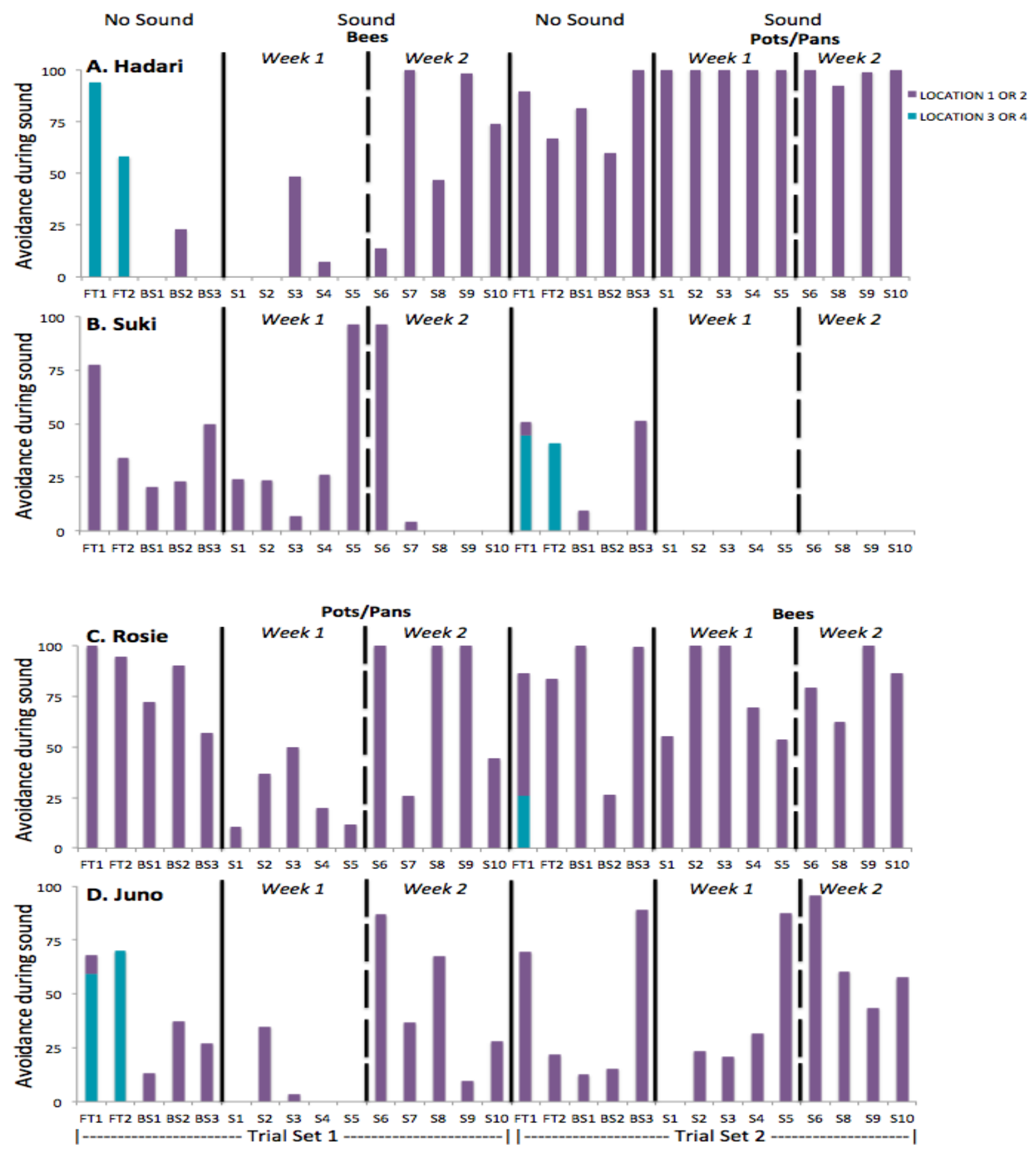

Figure 4. Avoidance (measured as percentage of time spent at an experimental location) during the sound playback: A. Hadari; B. Suki; C. Rosie; D. Juno. There were four experimental locations during the food training (FT) trials, but only one location (Location 1 or 2) during control sound (CS) and experimental sound (S) trials. Solid black lines separate no-sound and sound treatments, while dashed lines separate different weeks of the same sound treatment.

TS2 (Second sound). Two of the elephants, Suki (pots/pans) and Juno (bees), spent relatively lower percentages of time at the experimental location during the first three $\mathrm{S}$ trials $\left(X_{\mathrm{S}}=7.4 \pm 11.5 \%\right)$. compared to the CS trials $\left(X_{\mathrm{CS}}=29.7 \pm 34.0 \%\right)$ (Figure 4). As the sound trials continued, Juno increased her time spent at the location $\left(X_{\mathrm{S} 4, \mathrm{~S} 5}=59.6 \pm 39.4 \%\right)$. Suki, however, never visited the location during the sound 
trials. In contrast, Hadari (pots/pans) and Rosie (bees) spent similarly high percentages of time at the experimental location for the CS trials $\left(X_{\mathrm{CS}}=78.0 \pm 29.7 \%\right)$ and all $\mathrm{S}$ trials $\left(X_{\mathrm{S}}=92.6 \pm 18.2 \%\right)$ (Figure 4).
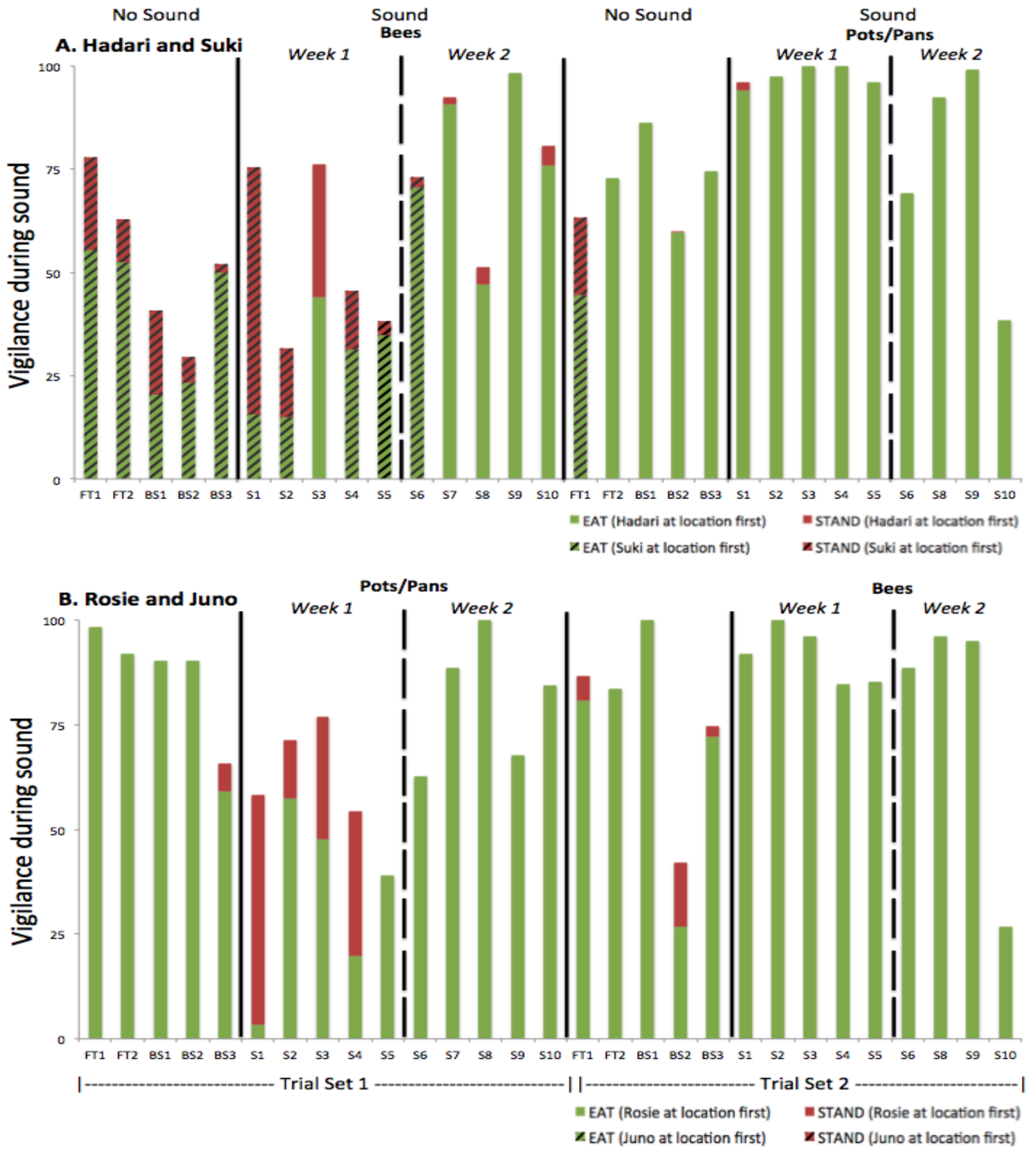

Figure 5. Vigilance (measured as percentage of time spent standing compared to eating) during the sound playback period: A. Hadari/Suki; B. Rosie/Juno. Shown are the results for only the first elephant to reach the experimental location during each pair's trial. Solid colored bars indicate that Hadari (A) or Rosie (B) was first. Patterned bars indicate that Suki (A) or Juno (B) was first, though Juno was never first to the location. Each trial set includes food training (FT) trials, control sound (CS) trials, and experimental sound (S) trials. Solid black lines separate no-sound and sound treatments; dashed lines separate different weeks of the same sound treatment. 


\section{Vigilance (\% Time Spent Standing versus Eating During Sound Playback)}

TS1 (First sound). The first elephant of both pairs stood for relatively higher percentages of time and ate for lower percentages of time during the first three $S$ trials $\left(X_{\text {Stand }}=34.5 \pm 19.2 \%, X_{\text {Eat }}=30.6 \pm\right.$ $22.0 \%)$ compared to the CS trials $\left(X_{\text {Stand }}=5.9 \pm 7.7 \%, X_{\text {Eat }}=55.6 \pm 30.8 \%\right)$ (Figure 5). As the sound trials continued, their percentages of time spent standing decreased, while the percentages of time spent eating increased $\left(X_{\text {Stand }}=4.7 \pm 9.4 \%, X_{\text {Eat }}=65.1 \pm 26.6 \%\right)$. For Hadari and Suki (bees), the first elephant reached baseline levels of standing and eating by S4. For Rosie and Juno (pots/pans), the first elephant reached baseline levels of standing and eating by S7.

TS2 (Second sound). The first elephant of both pairs stood for low percentages of time and ate for high percentages of time during CS trials $\left(X_{\text {Stand }}=3.1 \pm 6.1 \%, X_{\text {Eat }}=69.9 \pm 25.2 \%\right)$ and $S$ trials $\left(X_{\text {Stand }}=0.1\right.$ $\pm 0.5 \%, X_{\text {Eat }}=86.2 \pm 20.1 \%$ ) (Figure 5). The first elephant for Hadari and Suki (pots/pans) and Rosie and Juno (bees) stood and ate at baseline levels during S1. Their percentages of time spent standing and eating remained at baseline levels for the rest of the trial set, except S10 when both first elephants mudded for most of the sound-on time.

\section{Discussion}

The aim of this study was to examine how elephants responded to the two auditory stimuli - bee buzzing and banging on pots and pans - and whether they would stop responding to these stimuli with repeated exposure. As predicted, all four elephants initially exhibited distress, avoidance, and vigilance behaviors in response to both sounds. Specifically, the elephants initially responded to the sounds by increasing their distress rates and standing times, while decreasing their at-location times and eating times. The strongest reactions were exhibited by Rosie and Juno when presented with the pots/pans sound during TS1. However, with repeated presentations of each sound, the elephants' responses diminished to baseline levels, indicating that they habituated to both sounds. The elephants more quickly reduced their reactions to the second sound that they were presented (TS2) compared to the first sound (TS1), suggesting that a generalization of habituation had occurred between the two sounds.

In response to the sound presentations, the elephants initially exhibited a number of distress behaviors, such as alert, ear perk, and tail up (images of elephants exhibiting distress events can be seen in Figure 3). These behaviors are displayed by both captive and wild Asian and African elephants during various distressful situations (Table 2), such as anti-predator, defensive, or fearful contexts (Poole \& Granli, 2004). When an elephant is in distress, nearby conspecifics will often vocalize and physically touch the distressed elephant, which may be a means of reassurance (Douglas-Hamilton, Bhalla, Wittemyer, \& Vollrath, 2006; Plotnik \& de Waal, 2014). Rosie and Juno frequently vocalized (rumbles) back and forth during or immediately after the sound presentation. These elephants may have been communicating about the sound, their distress due to the sound, or attempting to console each other. The elephants also initially showed increased avoidance and vigilance responses to the sounds. Previous studies have observed that elephants move away from the presentation of Maasai tribesmen scent (Bates et al., 2007), capsicum spray (Osborn, 2002), and bee buzzing (King et al., 2007; Soltis et al., 2014). Wild elephants also froze when presented with infrasonic alarm calls from a familiar family group (O'Connell-Rodwell \& Wood, 2007). Standing, rather than eating, could help elephants focus more on the sound, and thereby locate its source and determine if they are in a potentially threatening situation. African ungulates typically spend less time foraging when predators are nearby, with a negative relationship between foraging and vigilance (Creel, Schuette, \& Christianson, 2014). The present study further confirms that elephants respond to potentially threatening stimuli, such as bee buzzing and banging on pots/pans, with distress, vigilance, and avoidance behaviors.

Competition for resources occurs between elephants in captivity (Freeman, Schulte, \& Brown, 2010) and in the wild (Archie, Morrison, Foley, Moss, \& Alberts, 2006). Throughout this study, Hadari and Suki were rarely observed eating at the same location and they were never observed eating from the same 
pile of hay. Suki spent little to no time at the experimental location starting on TS1's S7. This was also the trial when Hadari began walking immediately to the experimental location, and was the first elephant there from this trial onward. Thus, Suki may have stopped visiting the location due to competition and/or her dominance relationship with Hadari over access to the food. Since her avoidance may have been influenced by Hadari's presence, Suki's time spent at the experimental location may not be a good measure of her reaction to the sounds.

Unexpectedly, all four elephants exhibited stronger reactions to the pots/pans sound than to the bee sound. This occurred regardless of whether the pots/pans sound was presented first or second, though the strongest reactions were exhibited by Rosie and Juno when it was presented as their first sound. Hadari and Suki also exhibited higher distress rates during the first pots/pans sound trial (second sound) compared to their first bee sound trial (first sound), but this was less pronounced. The elephants' weaker reaction to the bee sound was not expected, as previous research suggests that elephants react to bee buzzing because it is a natural cue that a threat (bee swarm or hive) is nearby (King et al., 2007; 2009; Vollrath \& DouglasHamilton, 2002). Furthermore, we predicted that the elephants would habituate more quickly to the pots/pans sound because it was more similar to the human-generated noises, such as exhibit construction and maintenance. However, there are several potential explanations for our observed findings.

First, the higher frequency and intensity, as well as the possible unusualness of the pots/pans stimulus may have evoked stronger reactions from the Nashville elephants. Farmers bang metal objects together to frighten crop raiders away from their crops (Nelson et al., 2003). The intensity and unnaturalness of the sound could be what causes the wild animals to be frightened and leave the area. Large kangaroos (Macropus spp.), which are crop-raiders in Australia, also exhibit stronger responses (decreased feeding, increased vigilance/flight) to an artificial sound (whip crack) than to a natural sound (foot stomp) (Biedenweg, Parsons, Fleming, \& Blumstein, 2011). The auditory stimuli chosen for this experiment differed somewhat in frequency and intensity. It is possible that a natural sound with the same intensity and frequency as the artificial pots/pans sound would elicit the same level of response. Furthermore, if animals are frightened by an artificial sound because it is something that they do not experience in their natural habitat, then both natural and artificial sounds could be effective as crop-raiding deterrents (Biedenweg et al., 2011).

Second, the elephants may have required additional information that a beehive was close, such as olfactory or visual cues, or the possibility of being stung by bees. Since members of both pairs were still motivated to eat the hay during experimental trials, these results suggest that the sound of bee buzzing alone may not be enough to deter wild elephants from crop raiding over an extended period. This is similar to what has been observed in other species when presented with unimodal deterrents. For example, wolves (Canis lupus), American black bears (Ursus americanus), and coyotes (Canis latrans) rapidly habituate to visual depredation deterrents (Smith, Linnell, Odden, \& Swenson, 2000). Smith et al. (2000) suggest that habituation could be delayed if both visual and acoustic stimuli are used. Likewise, the establishment of active beehive fences around farms may be the best way to utilize elephants' fear of bees for humanelephant conflict mitigation (King et al., 2009). Not only do beehive fences provide auditory, visual, and olfactory cues for the presence of bees, but they also allow for the possibility of bee stings.

Third, because these particular elephants have lived in captivity for over 30 years, they may never have experienced African honeybees or they may have learned that the bees in the USA are not as aggressive as bees in Africa. Additionally, the authors were unable to determine the species of bees used in the recording, as it was obtained from an outside source. Although it is possible that these factors affected the results seen in this study, it is still unknown whether elephants' bee phobia is learned or innate. If innate, then the elephants would not require experience with Africanized bees to react to the sound. If learned, it may be a fear that is acquired early by elephants in the wild, through their own experiences or by social facilitation. As these elephants did show distress, avoidance, and vigilance reactions to the first bee sound presentations, it is probable that they possess a fear of bees like their wild counterparts.

After repeated presentations, the elephants gradually stopped responding to both the bee sound and pots/pans sound. Individuals can learn to reduce their responses to a stimulus through two processes: habituation and extinction. Both of these processes involve learning, but extinction specifically involves 
associative learning (McSweeney \& Swindell, 2002). If the elephants innately knew or socially learned that bee buzzing signified a nearby threat, then habituation would be the correct term for describing their reduced responses. If acquired through associative learning, then extinction would be more precise. It was not possible to determine how the elephants acquired their bee phobia. However, since elephants are social animals and calves stay with their mother until at least maturity (Archie, Moss, \& Alberts, 2006), it is more likely to be innate or socially learned than independently acquired by each elephant through associative learning. Furthermore, the elephants' reactions to the pots/pans sound were probably caused by its novelty rather than previous negative experiences. Consequently, habituation, not extinction, seems to be a more precise term to describe the elephants' reduced reactions to the sounds with repeated presentations.

As the elephants habituated to the sounds, their distress, avoidance, and vigilance responses decreased to levels observed when no sound was played. Previous habituation studies using other species have shown similar results (Deecke, Slater, \& Ford, 2002; Elmeros, Winbladh, Andersen, Madsen, \& Christensen, 2011; Raderschall, Magrath, \& Hemmi, 2011; Samuni, Mundry, Terkel, Zuberbuhler, \& Hobaiter, 2014). For example, as horses habituate to novel objects, they reduce their heart rates, fear-related behaviors, and distances from the object, while also increasing their feeding times (Christensen, Zharkikh, \& Chovaux, 2011; Leiner \& Fendt, 2011). Horses not only habituate to novel objects, but they also generalize their habituation between objects of the same color (Christensen, et al., 2008). Similarly, the elephants in the present study showed evidence of generalization between the two sounds. We do not think that elephants heard the sounds played in the yard while they were in the barn, a large, concrete structure some distance away. The handlers saw no reactions by these elephants and initially the elephants did respond to this sound during the second set of trials. All four elephants reached baseline levels more quickly during presentations of the second sound compared to the first sound. Although the two sounds were different in sound properties and evolutionary relevance, generalization may have occurred because both stimuli were auditory and presented from the same locations.

Habituation and generalization can be obstacles during the development of zoo enrichment programs and human-wildlife conflict (HWC) mitigation (Murphy, McSweeney, Smith, \& McComas, 2003; Quirke \& O'Riordan, 2011; Tarou \& Bashaw, 2007). The use of multiple stimuli that are randomly presented or perceived using different sensory modalities can help maintain novelty and delay habituation (Elmeros et al., 2011; Quirke \& O'Riordan, 2011; Smith et al., 2000). Although this was a preliminary study with a small sample size, it is likely that similar patterns will be observed in other elephants due to their extensive cognitive abilities and heavy reliance on audition and olfaction. Multimodal deterrents that use aversive chemicals, such as capsicum, combined with fear-inducing sounds, such as bee buzzing, could be effective for HEC mitigation. Farmers could establish multimodal fences that include both beehives and chili-tobacco grease on the ropes (Chelliah et al., 2010; King et al., 2009). Furthermore, chili powder catapults (Le Bel et al., 2010) could be used with the sound of bee buzzing to add a form of punishment that is missing from sound-only deterrents. Additionally, the use of only auditory deterrents could still be effective if multiple different types of sounds are presented on a randomized schedule. To reduce the chances of generalization, these auditory stimuli should be as different as possible, such as by using natural and artificial sounds, sounds of different frequencies and intensities, and sounds emitted from different locations. Both multimodal deterrents and randomized unimodal deterrents reduce the probability that elephants will repeatedly receive the same stimulus or generalize their habituation between different stimuli. However, if the value of the crops relative to wild forage is high enough, elephants and other crop raiders may tolerate a high degree of discomfort or perceived discomfort to obtain the food resource (Schulte, Freeman, Goodwin, Hollister-Smith, \& Rasmussen, 2007). It is important to establish management plans that recognize the potential for habituation (as well as generalization and tolerance) in both the context of frequently presented enrichment items in captivity and crop-raiding deterrents in the wild (Schakner \& Blumstein, 2013; Shivik, 2006; Smith et al., 2000).

Acquiring knowledge on the habituation process of elephants also provides information on the species' cognitive abilities. Elephants exhibit many forms of learning, such as associative, social, and insight learning (Desmond \& Laule, 1991; Foerder et al., 2011; Plotnik et al., 2011). African and Asian elephants use their learning abilities to maintain social cohesion in their large family/bond groups and deal 
with the challenges of a dynamic environment (Bates et al., 2007; McComb et al., 2014, Plotnik et al., 2014; Soltis et al., 2014). Both species are currently listed on the IUCN Red List of Threatened Species (IUCN, 2014), and having knowledge on the cognitive abilities of animals can improve the effectiveness of conservation efforts, as well as captive breeding, rehabilitation, and reintroductions (Paz-y-Miño-C, 2014). Elephant habitat in the wild has become smaller and more fragmented because of deforestation and human development, resulting in higher incidences of HEC (Nelson et al., 2003). As pressure from habitat loss and poaching continue to threaten elephant survival, developing more effective HEC mitigation methods and solving other conservation issues will become increasingly more essential. There could also be an increasing need to keep elephants in some form of captivity or enclosed range to protect them from extinction. With more knowledge on elephant cognition, facilities housing or otherwise responsible for such elephants can better implement management plans with enrichment designed to keep their elephants mentally and physically healthy (Irie \& Hasegawa, 2009). Habituation is an important learning process that should be considered when studying cognition, developing enrichment approaches for animals housed in captivity, and implementing human-wildlife conflict mitigation strategies.

\section{Acknowledgements}

We gratefully acknowledge Katherine Chrisman and Kaley Burden for their help conducting this research, as well as the Nashville Zoo, their elephant handers and veterinarian staff for permitting this study to occur at their facility. We also thank Danielle Brown, Sharon Mutter, and Michael Smith for their constructive feedback on this manuscript before submission. This study was approved by Western Kentucky University, IACUC 14-10. Funding provided by Western Kentucky Graduate Student Research Grant.

\section{References}

Archie, E. A., Morrison, T. A., Foley, C. A. H., Moss, C. J., \& Alberts, S. C. (2006). Dominance rank relationships among wild female African elephants, Loxodonta africana. Animal Behaviour, 71, 117-127.

Archie, E. A., Moss, C. J., \& Alberts, S. C. (2006). The ties that bind: Genetic relatedness predicts the fission and fusion of social groups in wild African elephants. Proceedings of the Royal Society, 273, 513-522.

Bates, L. A., Lee, P. C., Nijiraini, N., Poole, J. H., Sayialel, K., Sayialel, S., ...Byrne, R. W. (2008). Do elephants show empathy? Journal of Consciousness Studies, 15, 204-225.

Bates, L. A., Poole, J. H., \& Byrne, R. W. (2008). Elephant cognition. Current Biology, 18, R544-R546.

Bates, L. A, Sayialel, K. N, Nijiraini, N. W, Moss, C. J, Poole, J. H, \& Byrne, R. W. (2007). Elephants classify human ethnic groups by odor and garment color. Current Biology, 17, 1938-1942.

Bejder, L., Samuels, A., Whitehead, H., Finn, H., \& Allen, S. (2009). Impact assessment research: Use and misuse of habituation, sensitisation and tolerance in describing wildlife responses to anthropogenic stimuli. Marine Ecology Progress Series, 395, 177-185.

Biedenweg, T. A., Parsons, M. H., Fleming, P. A., \& Blumstein, D. T. (2011). Sounds scary? Lack of habituation following the presentation of novel sounds. PLOS ONE, 6, e14549. doi: 10.1371/journal.pone.0014549

Bouley, D. M., Alarcon, C. N., Hildebrandt, T., \& O'Connell-Rodwell, C.E. (2007). The distribution, density and three-dimensional histomorphology of Pacinian corpuscles in the foot of the Asian elephant (Elephas maximus) and their potential role in seismic communication. Journal of Anatomy, 211, 428-435.

Breed, M. D., Guzmán-Novoa, E., \& Hunt, G. J. (2004). Defensive behavior of honey bees: Organization, genetics and comparisons with other bees. Annual Review of Entomology, 49, 271-298.

Breiter, H. C., Etcoff, N. L., Whalen, P. J., Kennedy, W. A., Rauch, S. L., Buckner, R. L., ...Rosen, B. R. (1996). Response and habituation of the human amygdala during visual processing of facial expression. Neuron, 17, 875-887.

Brown, G. D. (1998). Nonassociative learning processes affecting swimming probability in the seaslug Tritonia diomedea: Habituation, sensitization and inhibition. Behavioural Brain Research, 95, 151-165.

Chelliah, K., Kannan, G., Kundu, S., Abilash, N., Madhusudan, A., Baskaran, N., \& Sukumar, R. (2010). Testing the efficiency of a chilli-tobacco rope fence as a deterrent against crop-raiding elephants. Current Science, 99, 1239-1243. 
Christensen, J. W., Zharkikh, T., \& Chovaux, E. (2011). Object recognition and generalization during habituation in horses. Applied Animal Behaviour Science, 129, 83-91.

Christensen, J. W., Zharkikh, T., \& Ladewig, J. (2008). Do horses generalize between objects during habituation? Applied Animal Behaviour Science, 114, 509-520.

Clayton, N., \& Emery, N. (2005). Corvid cognition. Current Biology, 15, R80-R81.

Connor, R. C., \& Smolker, R. S. (1985). Habituated dolphins (Tursiops sp.) in Western Australia. Journal of Mammalogy, 66, 398-400.

Creel, S., Schuette, P., \& Christianson, D. (2014). Effects of predation risk on group size, vigilance, and foraging behavior in an African ungulate community. Behavioural Ecology, 24, 773-784.

Davies, T. E., Wilson, S., Hazarika, N., Chakrabarty, J., Das, D., Hodgson, D. J., \& Zimmermann, A. (2011). Effectiveness of intervention methods against crop-raiding elephants. Conservation Letters, 4, 346-354.

De Boer, W. F. \& Baquete, D. S. (1998). Natural resource use, crop damage and attitudes of rural people in the vicinity of the Maputo Elephant Reserve, Mozambique. Environmental Conservation, 25, 208-218.

Deecke, V. B., Slater, P. J. B., \& Ford, J. K. B. (2002). Selective habituation shapes acoustic predator recognition in harbour seals. Nature, 420, 171-173.

Desmond, T. J., \& Laule, G. (1991). Protected-contact elephant training. AAZPA Annual Conference Proceedings (pp. 606-613). Silver Springs, MD.

Dinets, V. (2015). Play behavior in crocodilians. Animal Behavior and Cognition, 2, 49-55.

Douglas-Hamilton, I., Bhalla, S., Wittemyer, G., \& Vollrath, F. (2006). Behavioural reactions of elephants toward a dying and deceased matriarch. Applied Animal Behaviour Science, 100, 87-102.

Eisenstein, E. M., Eisenstein, D., \& Smith, J. C. (2001). The evolutionary significance of habituation and sensitization across phylogeny: A behavioral homeostasis model. Integrative Psychological and Behavioral Science, 36, 251-265.

Elmeros, M., Winbladh, J. K., Andersen, P. N., Madsen, A. B., \& Christensen, J. T. (2011). Effectiveness of odour repellents on red deer (Cervus elaphus) and roe deer (Capreolus capreolus): A field test. European Journal of Wildlife Research, 57, 1223-1226.

Epple, G., Mason, J. R., Aronov, E., Nolte, D. L., Hartz, R. A., Kaloostian, R., ...Smith, A. B. (1995). Feeding responses to predator-based repellents in the mountain beaver (Aplodontia rufa). Ecological Applications, 5, 163-1170.

Foerder, P., Galloway, M., Barthel, T., Moore, D. E., \& Reiss, D. (2011). Insightful problem solving in an Asian elephant. PLoS ONE, 6, e23251. doi: 10.1371/journal.pone.0023251

Freeman, E. W., Schulte, B. A., \& Brown, J. L. (2010). Investigating the impact of rank and ovarian activity on the social behavior of captive female African elephants. Zoo Biology, 29, 154-167.

Goodyear, S. E. (2015). Habituation to auditory stimuli by captive African elephants (Loxodonta africana) (unpublished master's thesis). Western Kentucky University, Kentucky, USA.

Graham, J. E., Karmarkar, A. M., \& Ottenbacher, K. J. (2012). Small sample research designs for evidence-based rehabilitation: Issues and methods. Archives of Physical Medicine and Rehabilitation, 93, S111-S116. doi: 10.1016/j.apmr.2011.12.017

Groves, P. M., Lee, D., \& Thompson, R. F. (1969). Effects of stimulus frequency and intensity on habituation and sensitization in acute spinal cat. Physiology \& Behavior, 4, 383-388.

Groves, P. M., \& Thompson, R. F. (1970). Habituation: A dual-process theory. Psychological Review, 55, 419-450.

Hill, C. M. (1997). Crop-raiding by wild vertebrates: The farmer's perspective in an agricultural community in western Uganda. International Journal of Pest Management, 43, 77-84.

Hoare, R. (2011). Lessons from 15 years of human-elephant conflict mitigation: Management considerations involving biological, physical and governance issues in Africa. Pachyderm, 51, 60-73.

Irie, N., \& Hasegawa, T. (2009). Elephant psychology: What we know and what we would like to know. Japanese Psychological Research, 51, 177-181.

[IUCN] International Union for Conservation of Nature. (2014). IUCN Red List of Threatened Species. Version 2014.3. www.iucnredlist.org. Accessed February 13, 2015.

Johns, B. G. (1996). Responses of chimpanzees to habituation and tourism in the Kibale Forest, Uganda. Biological Conservation, 78, 257-262.

King, L. E., Douglas-Hamilton, I., \& Vollrath, F. (2007). African elephants run from the sound of disturbed bees. Current Biology, 17, R832-R833.

King, L. E., Lawrence, A., Douglas-Hamilton, I., \& Vollrath, F. (2009). Beehive fence deters crop-raiding elephants. African Journal of Ecology, 47, 131-137. 
King, L. E., Soltis, J., Douglas-Hamilton, I., Savage, A., \& Vollrath, F. (2010). Bee threat elicits alarm call in African elephants. PLoS ONE, 5, e10346. doi: 10.1371/journal.pone.0010346

Langbauer, W. R. Jr. (2000). Elephant communication. Zoo Biology, 19, 425-445.

Le Bel, S., Taylor, R., Lagrange, M., Ndoro, O., Barra, M., \& Madzikanda, H. (2010). An easy-to-use capsicum delivery system for crop-raiding elephants in Zimbabwe: Preliminary results of a field test in Hwange National Park. Pachyderm, 47, 80-89.

Lee, P. C. (1987). Allomothering among African elephants. Animal Behaviour, 35, $27-291$.

Leiner, L., \& Fendt, M. (2011). Behavioural fear and heart rate responses of horses after exposure to novel objects: Effects of habituation. Applied Animal Behaviour Science, 13, 104-109.

McComb, K., Shannon, G., Durant, S. M., Sayialel, K., Slotow, R., Poole, J., \& Moss, C. (2011). Leadership in elephants: The adaptive value of age. Proceedings of the Royal Society B, 278, 3270-3276. doi: 10.1098/rspb.2011.0168

McComb, K., Shannon, G., Sayialel, K. N., \& Moss, C. (2014). Elephants can determine ethnicity, gender, and age from acoustic cues in human voices. Proceedings of the National Academy of Sciences, 111, 5433-5438.

McSweeney, F. K., \& Swindell, S. (2002). Common processes may contribute to extinction and habituation. The Journal of General Psychology, 129, 364-400.

Morgan, K. N., \& Tromborg, C. T. (2007). Sources of stress in captivity. Applied Animal Behaviour Science, 102, 262-302.

Murphy, E. S., McSweeney, F. K., Smith, R. G., \& McComas, J. J. (2003). Dynamic changes in reinforce effectiveness: Theoretical, methodological, and practical implications for applied research. Journal of Applied Behavior Analysis, 36, 421-438.

Nelson, A., Bidwell, P., \& Sillero-Zubiri, C. (2003). A review of human-elephant conflict management strategies. Oxford, UK: People and Wildlife Initiative, Wildlife Conservation Research Unit.

Nyirenda, V. R., Myburgh, W. J., \& Reilly, B. K. (2012). Predicting environmental factors influencing crop raiding by African elephants (Loxodonta africana) in the Luangwa Valley, eastern Zambia. African Journal of Environmental Science and Technology, 6, 391-400.

O’Connell-Rodwell, C. E., \& Wood, J. D. (2007). Wild African elephants (Loxodonta africana) discriminate between familiar and unfamiliar conspecific seismic alarm calls. The Journal of the Acoustical Society of America, $122,823-830$.

Olson, D. (2004). Elephant husbandry resource guide. Lawrence, KS: Allen Press.

Osborn, F. V. (2002). Capsicum oleoresin as an elephant repellent: Field trials in the communal lands of Zimbabwe. The Journal of Wildlife Management, 66, 674-677.

Osborn, F. V., \& Parker, G. E. (2002). Living with elephants II: A manual for implementing an integrated programme to reduce crop loss to elephants and to improve livelihood security. Chisipite, Zimbabwe: Mid Zambezi Elephant Project.

Osborn, F. V., \& Rasmussen, L. E. L. (1995). Evidence for the effectiveness of an oleo-resin capsicum aerosol as a repellent against wild elephants in Zimbabwe. Pachyderm, 20, 55-64.

Osvath, M., Osvath, H., \& Bååth, R. (2014). An exploration of play behaviors in raven nestlings. Animal Behavior and Cognition, 1, 157-165.

Oswin Perera, B. M. A. (2009). The human-elephant conflict: A review of current status and mitigation methods. Gajaha, 30, 41-52.

Paz-y-Miño-C, G. (2014). Cognitive repertoire, cognitive legacies, and collective reasoning: The next frontiers in conservation behavior. In Yasukawa K (Ed.), Animal behavior: How and why animals do the things they do. Volume 3, Integration and application with case studies (pp. 289-310). Santa Barbara, California: ABCCLIO Publishers.

Plotnik, J. M., \& de Waal, F. B. M. (2014). Asian elephants (Elephas maximus) reassure others in distress. PeerJ, 2, e278. doi: $10.7717 /$ peerj. 278

Plotnik, J. M., Lair, R., Suphachoksahakun, W., \& de Waal, F. B. M. (2011). Elephants know when they need a helping trunk in a cooperative task. Proceedings of the National Academy of Sciences, 108, 5116-5121.

Plotnik, J. M., Pokorny, J. J., Keratimanochaya, T., Webb, C., Beronja, H. F., Hennessy, A., ... Getz, D. (2013). Visual cues given by humans are not sufficient for Asian elephants (Elephas maximus) to find hidden food. PLoS ONE, 8, e61174. doi: 10.1371/journal.pone.0061174

Plotnik, J. M., Shaw, R. C., Brubaker, D. L., Tiller, L. N., \& Clayton, N. S. (2014). Thinking with their trunks: Elephants use smell but not sound to locate food and exclude nonrewarding alternatives. Animal Behaviour, 88, 91-98. 
Poole, J. H., \& Granli, P. K. (2004). The visual, tactile and acoustic signals of play in African savannah elephants. In J. Jayewardene (Ed.), Endangered elephants, past present \& future (pp. 44-50). Proceedings of the Symposium on Human Elephant Relationships and Conflicts, Sri Lanka, September 2003. Colombo: Biodiversity \& Elephant Conservation Trust.

Poole, J. H., Tyack, P. L., Stoeger-Horwath, A. S., \& Watwood, S. (2005). Elephants are capable of vocal learning. Nature, 434, 455-456.

Quirke, T., \& O'Riordan, R. M. (2011). The effect of a randomised enrichment treatment schedule on the behaviour of cheetahs (Acinonyx jubatus). Applied Animal Behaviour Science, 135, 103-109.

Raderschall, C. A., Magrath, R. D., \& Hemmi, J. M. (2011). Habituation under natural conditions: Model predators are distinguished by approach direction. Journal of Experimental Biology, 214, 4209-4216.

Rasmussen, L. E. L, \& Schulte, B. A. (1998). Chemical signals in the reproduction of Asian and African elephants. Animal Reproduction Science, 53, 19-34.

Roberts, D. (2014). Rapid habituation by mosquito larvae to predator kairomones. Journal of Vector Ecology, 39, 355-360.

Samuni, L., Mundry, R., Terkel, J., Zuberbuhler, K., \& Hobaiter, C. (2014). Socially learned habituation to human observers in wild chimpanzees. Animal Cognition, 17, 997-1005.

Sarkar, A. (2003). Fundamentals of Animal Behaviour (pp. 144). New Delhi: Discovery Publishing House.

Schakner, Z. A., \& Blumstein, D. T. (2013). Behavioral biology of marine mammal deterrents: A review and prospectus. Biological Conservation, 167, 380-389.

Schulte, B. A., Freeman, E., Goodwin, T. E., Hollister-Smith, J., \& Rasmussen, L. E. L. (2007). Honest signaling through chemicals by elephants with applications for conservation and care. Applied Animal Behaviour Science, 102, 344-363.

Shivik, J. A. (2006). Tools for the edge: What's new for conserving carnivores. Bioscience, 56, $253-259$.

Sitati, N. W., Walpole, M. J., Smith, R. J., \& Leader-Williams, N. (2003). Predicting spatial aspects of human-elephant conflict. Journal of Applied Ecology, 40, 667-677.

Smith, M. E., Linnell, J. D. C., Odden, J., \& Swenson, J. E. (2000). Review of methods to reduced livestock depredation II. Aversive conditioning deterrents and repellents. Acta Agriculturae Scandinavica, Section A, 50, 304-315.

Soltis, J., King, L. E., Douglas-Hamilton, I., Vollrath, F., \& Savage, A. (2014). African elephant alarm calls distinguish between threats from humans and bees. PLoS ONE, 9, e89403. doi: 10.1371/journal.pone.0089403

Stoinski, T. S., Daniel, E., \& Maple, T. L. (2000). A preliminary study of the behavioral effects of feeding enrichment on African elephants. Zoo Biology, 19, 485-493.

Tarou, L. R., \& Bashaw, M. J. (2007). Maximizing the effectiveness of environmental enrichment: Suggestions from the experimental analysis of behavior. Applied Animal Behaviour Science, 102, 189-204.

Thompson, R. F., \& Spencer, W. A. (1966). Habituation: A model phenomenon for the study of neuronal substrates of behavior. Psychological Review, 73, 16-43.

Thuppil, V., \& Coss, R. G. (2013). Wild Asian elephants distinguish aggressive tiger and leopard growls according to perceived danger. Biology Letters, 9, 20130518. doi: 10.1098/rsbl.2013.0518

Thuppil, V., \& Coss, R. G. (2015). Playback of felid growls mitigates crop-raiding by elephants Elephas maximus in southern India. Oryx FirstView Article doi: 10.1017/S0030605314000635

Ujvári, M. L., Baagøe, H. J., \& Madsen, A. B. (1998). Effectiveness of wildlife warning reflectors in reducing deervehicle collisions: A behavioral study. Journal of Wildlife Management, 62, 1094-1099.

Vollrath, F., \& Douglas-Hamilton, I. (2002). African bees to control African elephants. Naturwissenschaften, 89, 508511.

Wells, D. L., \& Irwin, R. M. (2008). Auditory stimulation as enrichment for zoo-housed Asian elephants (Elephas maximus). Animal Welfare, 17, 335-340.

Whitley, B. E., \& Kite, M. E. (2012). Principles of Research in Behavioral Science, 3rd Edition (pp. 362-396). New York: Routledge.

Wiedenmayer, C. (1998). Food hiding and enrichment in captive Asian elephants. Applied Animal Behaviour Science, 56, 77-82.

Ylönen, H., Eccard, J. A., Jokinen, I., \& Sundell, J. (2006). Is the antipredatory response in behaviour reflected in stress measured in faecal corticosteroids in a small rodent? Behavioral Ecology and Sociobiology, 60, 350358. 